\title{
Update on Dermoscopy and Infectious Skin Diseases
}

\author{
Vincenzo Piccolo ${ }^{1}$
}

1 Dermatology Unit, University of Campania Luigi Vanvitelli, Naples, Italy

Key words: dermatoscopy, dermoscopy, infections, infectious, entomodermoscopy

Citation: Piccolo V. Update on dermoscopy and infectious skin diseases. Dermatol Pract Concept. 2020;10(1):e2020003. DOI: https://doi. org/10.5826/dpc.1001a03

Accepted: September 7, 2019; Published: December 31, 2019

Copyright: (@2019 Piccolo. This is an open-access article distributed under the terms of the Creative Commons Attribution License, which permits unrestricted use, distribution, and reproduction in any medium, provided the original author and source are credited.

Funding: None.

Competing interests: The author has no conflicts of interest to disclose.

Authorship: The author takes responsibility for this publication.

Corresponding author: Vincenzo Piccolo, MD, II Policlinico, Edificio 9c, Primo piano, Via Pansini 5 - 80131 Napoli, Italy. Email: piccolo. vincenzo@gmail.com

ABSTRACT Nowadays, dermoscopy is a global worldwide diffuse diagnostic tool supporting clinicians in their daily hard task of correct orientation among dermatological diseases. Born to be an instrument for early diagnosis of skin cancer, the dermatoscope is now considered the dermatologist's stethoscope, as it can be routinely used to support diagnosis in general dermatology, so spreading its utility in cutaneous inflammatory and infectious diseases, as adjuvant and not substitute to histology and potassium hydroxide examination. As concerns the latter, plenty of papers have been published since the first description of dermoscopic findings of scabies. The aim of this review is to give the clinician a practical approach to dermoscopic parameters of cutaneous infectious diseases with a focus on the latest updates in this topic.

\section{Introduction}

Nowadays, dermoscopy is a global worldwide diffuse diagnostic tool supporting clinicians in their daily hard task of correct orientation among dermatological diseases [1]. Born to be an instrument for early diagnosis of skin cancer, the dermatoscope is now considered the dermatologist's stethoscope [2], as it can be routinely used to support diagnosis in general dermatology, so spreading its utility in cutaneous inflammatory and infectious diseases. As concerns the latter, plenty of papers have been published since the first description of dermoscopic findings of scabies [3].

A galloping enthusiasm toward dermoscopy in recent years induced dermatologists all over the world to describe everyday novel dermoscopic signs in almost every dermatological disease, thus sometimes generating confusion in termi- nology. A recent consensus by the International Dermoscopy Society tried to put order in that confusion by redefining the most accepted dermoscopic criteria and terminology in inflammatory and infectious diseases of skin [4].

As a general consideration, when approaching cutaneous infectious diseases (entomodermoscopy), a risk of spreading the infection through the dermatoscope does exist $[5,6]$, but a few recommendations can limit or avoid the issue. First, noncontact dermoscopy should be preferred as the diagnostic approach and nowadays it is easier because of growing diffusion of polarized handled dermatoscopes, which avoid skin contact. Second, the use of antiseptics and instrument disinfection after each use is mandatory. The use of disposable transparent devices has been abandoned because of interference with the correct visualization of the skin. 


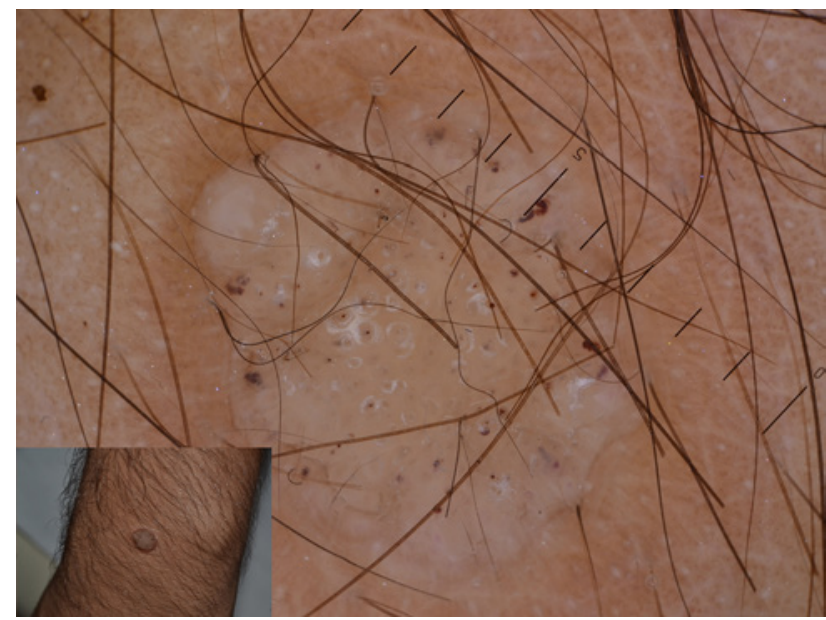

Figure 1. Typical papillae in a common wart centered by hemorrhagic dots in turn surrounded by whitish halos.

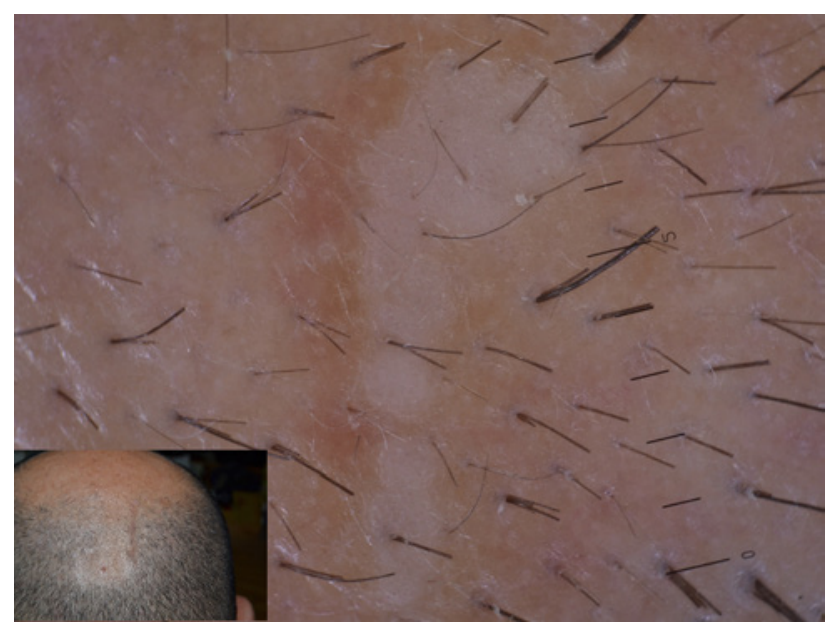

Figure 3. Dotted vessels on a whitish background found in flat warts of the scalp.

The aim of this review is to give the clinician a practical approach to dermoscopic parameters of cutaneous infectious diseases with a focus on the latest updates in this topic.

\section{Human Papillomavirus Infections}

Human papillomavirus infections are among the most common cutaneous infections in human beings, as the human papillomavirus is ubiquitous and its clinical expression can be extremely variable. From this clinical variability, a variegate presentation of dermoscopic findings derives. There is a constant feature that can often be observed in warts, ie, dotted vessels and/or hemorrhagic points that can be variably found in different kinds of viral warts.

Common warts. Common warts are the most frequent type of warts. They can appear on any part of the body, although hands represent the most affected area. Common warts usually show at dermoscopy as grouped papillae, with dotted or loop vessels, and/or hemorrhagic points and lines

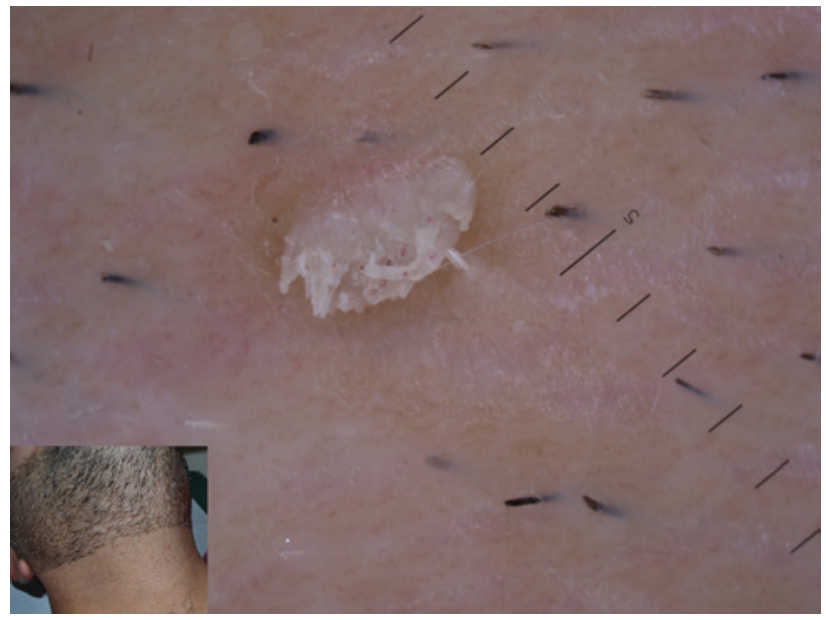

Figure 2. Projected papillae in a filiform wart of beard area. Dotted vessels are detectable at the extremities of each papilla.

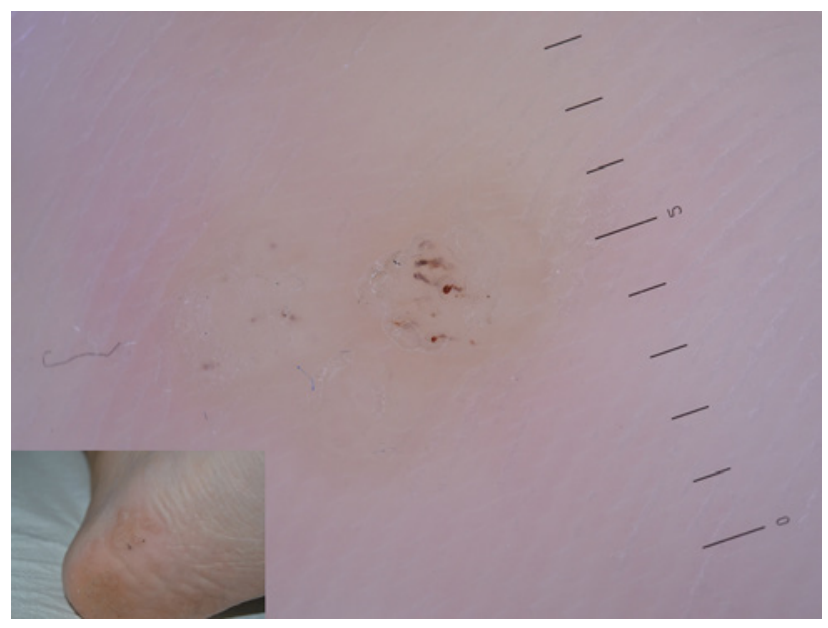

Figure 4. Plantar wart showing hemorrhagic dots corresponding to thrombosed vessels. Interruption of dermatoglyphics is clearly evident.

often surrounded by a whitish halo (Figure 1), assuming a "frogspawn appearance" [7].

Filiform warts. Filiform warts often appear in periorificial areas, mostly in children or in the beard area of men. Dermoscopy shows the same features as common warts, with more prevalent papillae [7] (Figure 2).

Flat warts. Flat warts present as plane-topped papules, often spread on the face or dorsa of hands. Dermoscopy observation may be difficult because of lack of striking findings, although small dotted vessels on a yellowish background may be seen (Figure 3). These features may be helpful to distinguish flat warts from folliculitis or acne, usually showing follicular findings [7].

Plantar warts. Among the most common type of warts, plantar warts show at dermoscopy as small dotted hemorrhagic structures corresponding to thrombosed vessels, visible in the context of whitish or yellowish papillae which interrupt cutaneous dermatoglyphics (Figure 4). Easy to recognize, plantar warts are sometimes misdiagnosed as tylomas 


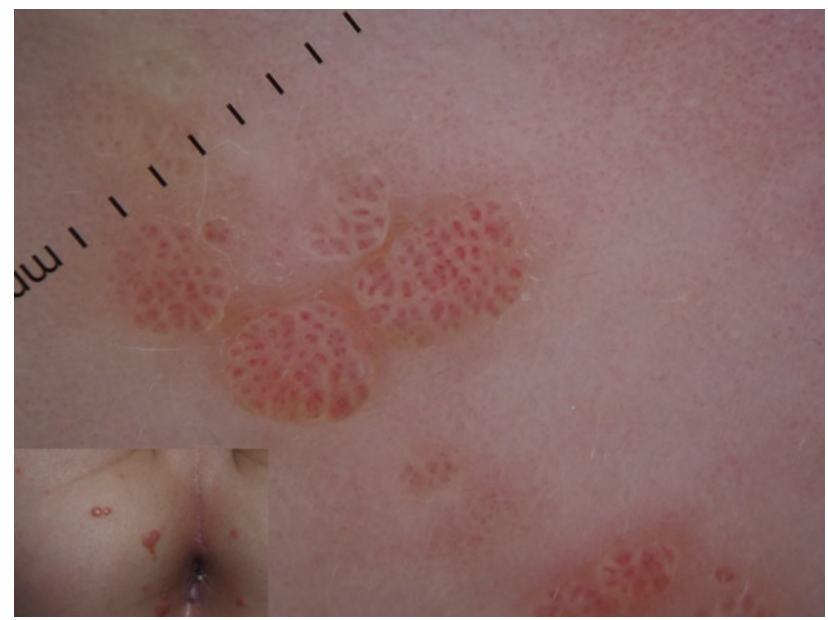

Figure 5. Mosaic pattern in anogenital warts of a child.

(hyperkeratosis without interruption of dermatoglyphics) and must be distinguished from acral melanoma, sometimes unfortunately misinterpreted as wart [7].

Genital warts. The sexually transmitted disease of our century, genital warts or condylomata, are quite easy to diagnose, although in early stages dermoscopy could be very useful to avoid overdiagnosis and distinction from noninfectious genital lesions often misdiagnosed as warts, ie, hirsuties penis, vestibular papillomatosis, Fordyce granules, and genital angiokeratomas.

The most common dermoscopic finding is the so-called mosaic pattern, ie, the presence of grouped dotted or glomerular vessels at center surrounded by a whitish network (Figure 5). The papillae can sometimes project outward. Pigmented genital warts can be occasionally observed, and they usually show at dermoscopy a cerebriform or seborrheic keratosis-like appearance [7].

\section{What's New?}

A recent study has investigated dermoscopic features of urethral condylomata [8], showing as expected a predominance of vessels that can vary in morphology from more common dotted to polymorphous vessels, but the authors recommend biopsy to confirm the diagnosis.

\section{Molluscum Contagiosum}

Molluscum contagiosum (MC) is a very common infection caused by poxvirus, potentially occurring at any age and body location, more frequent in atopic children or in adults as sexually transmitted disease. It typically appears with single or multiple variably-sized translucent papules, sometimes umbilicated. Clinical diagnosis is quite easy, mostly in multiple lesions. In MC presenting as a single lesion, differential diagnosis may be challenging. Dermoscopy usually shows the

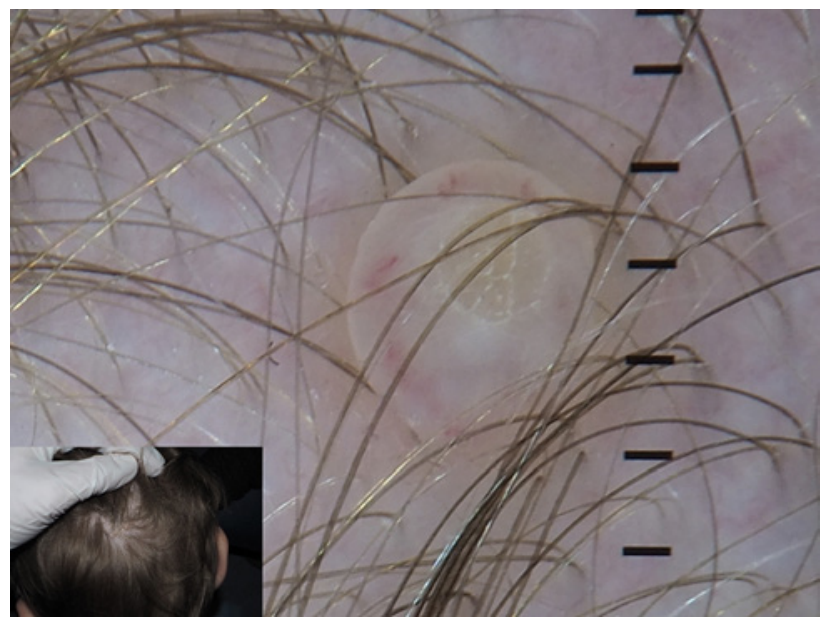

Figure 6. Typical dermoscopic appearance of molluscum contagiosum, showing a central pore on whitish amorphous structure surrounded by linear vessels.

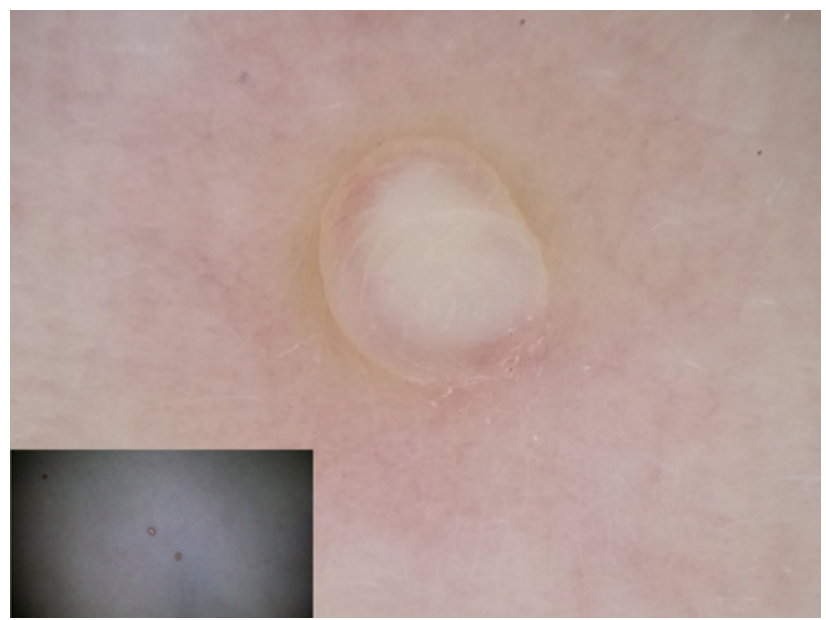

Figure 7. The presence of central orifice is not mandatory in molluscum contagiosum as in this case.

presence of a central pore on a white-yellowish amorphous area, often surrounded by thin crown vessels [7] (Figure 6). A large variation in dermoscopic findings of $\mathrm{MC}$ has been reported [9], regarding both central structures and vessels. Central pore may be absent (Figure 7), with the only central amorphous area detectable at dermoscopic examination. On the other hand, vessels may be visible or not and, when present, they can show different patterns, such as crown, radial, or dotted [9].

\section{What's New?}

With handled dermatoscope, the correct detection of vessels is not always easy because of pressure induced by the dermatoscope itself on the lesion. An interesting paper by Ku et al [10] has correlated features of white structures in MC to histopathology. The authors have recognized 3 types of central white structures in relation to the size, duration, and histopathology of MC. Classic MC presents with a central roundish white 


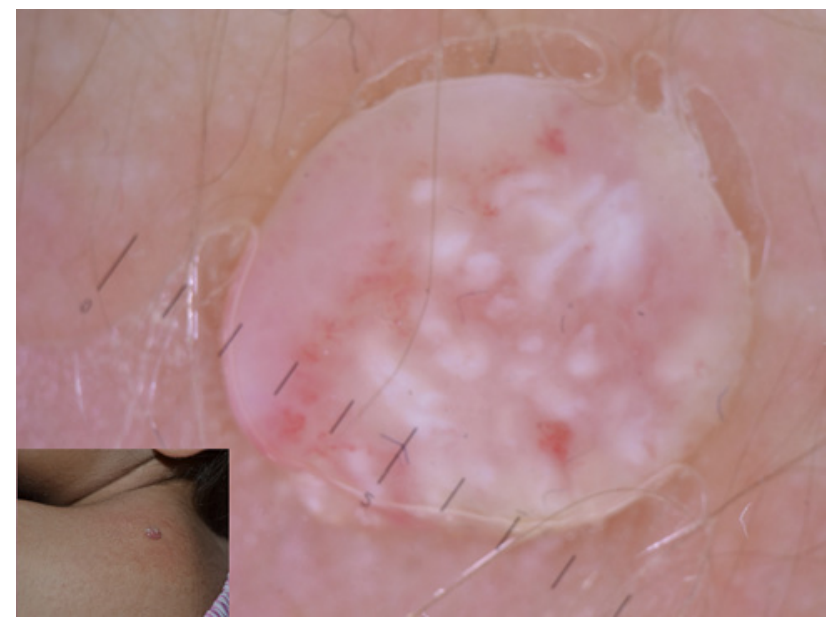

Figure 8. Polylobular appearance of an "old" molluscum of the dorsum.

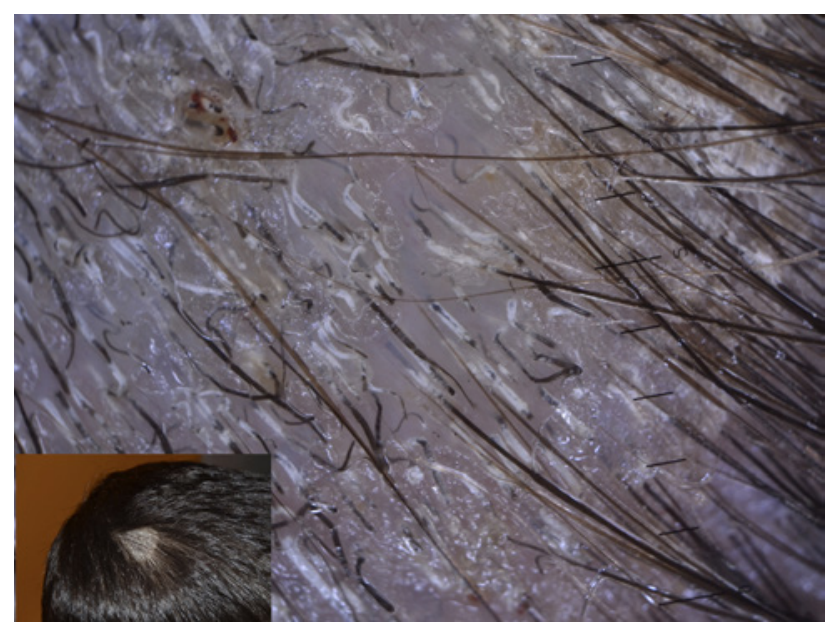

Figure 10. Tinea capitis showing different findings including comma hair, hair casts, dystrophic hairs, and zig-zag hair.

area. On the other hand, small and "young" lesions usually show a 4-leaf-clover-like appearance, whereas large and "old" $\mathrm{MC}$ is characterized by a polylobular appearance (Figure 8).

\section{Dermatophytic Infections}

Among dermatophytic infections, tinea capitis (TC) is the one that took most diagnostic advantage from the use of dermoscopy over time. TC is a common dermatophytosis of the scalp of children and rarely adults. Several agents have been isolated in patients with TC, with Microsporum canis being the most common in Europe, accounting for $80 \%$ of cases, followed by Trichophyton spp, progressively increasing as etiological agent of TC. Single or multiple alopecic scaly patches of the scalp are the usual clinical presentation of TC, whose diagnosis should be confirmed by potassium hydroxide examination and microbiological culture [11]. Although it can be easily recognized on the basis of clinical findings, dermoscopy may find a great role in differential diagnosis with

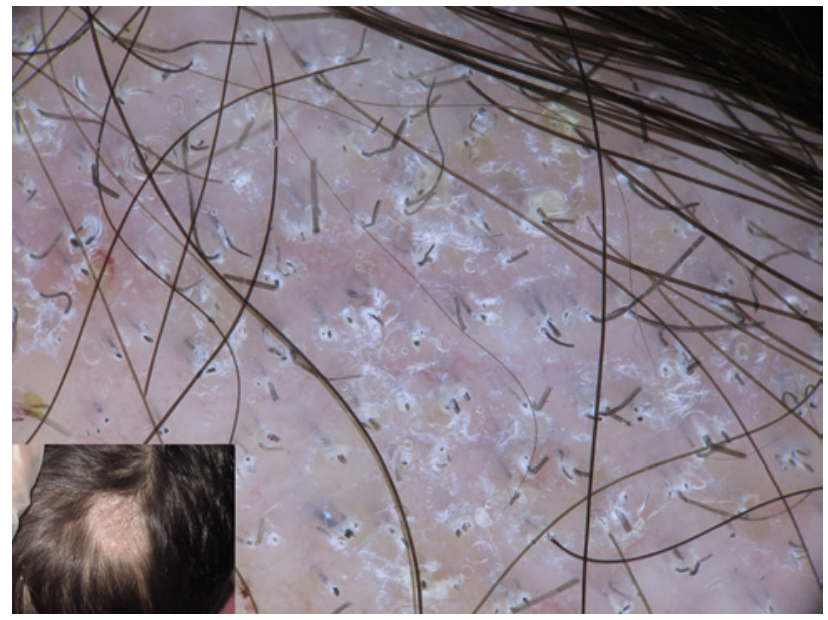

Figure 9. Diffuse comma hair in a patients affected by tinea capitis.

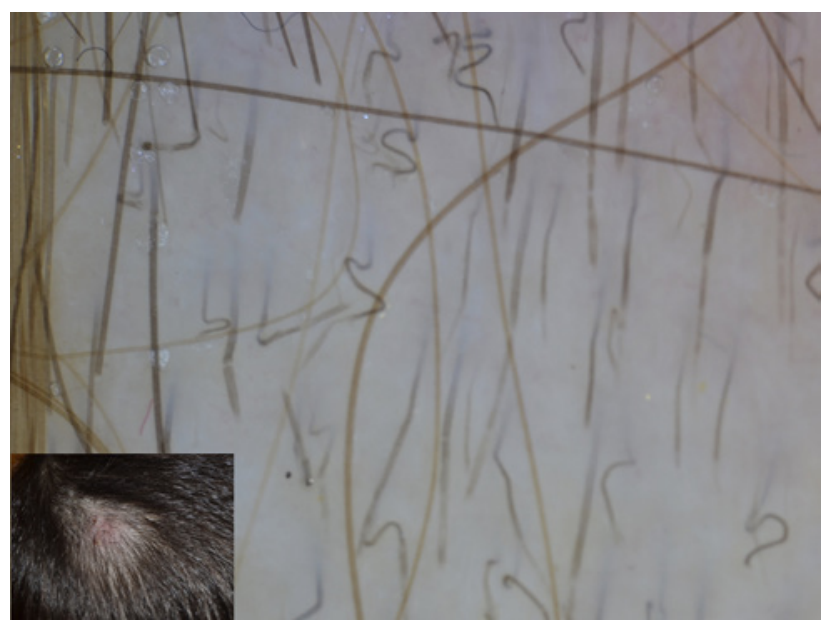

Figure 11. Corkscrew and barcode-like hair in tinea capitis.

other common causes of hair loss, especially in children, such as alopecia areata and trichotillomania. The most common and first described trichoscopic finding in TC is the so called "comma hair," ie, a shortened, curved hair resulting from the fungal invasion of the shaft [11] (Figure 9). Other nonspecific dermoscopic findings have been reported in TC, namely black dots, dystrophic hairs, and hair casts [11] (Figure 10).

\section{What's New?}

Tinea capitis. Recently, plenty of novel dermoscopic findings have been detected in TC, in particular zig-zag hair [12] (ie, hair with multiple breakage bands provoking bending of the hair shaft in different areas), corkscrew hair [12] (the equivalent finding of comma hair in patients with curly hair) (Figure 11), and the highly specific Morse code-like or barcode hairs [13], visible at high magnification with multiple horizontal transparent bands along the hair shaft. Another piece of news comes from the potential correlation between etiology and dermoscopy in TC. Indeed, a preliminary observation 


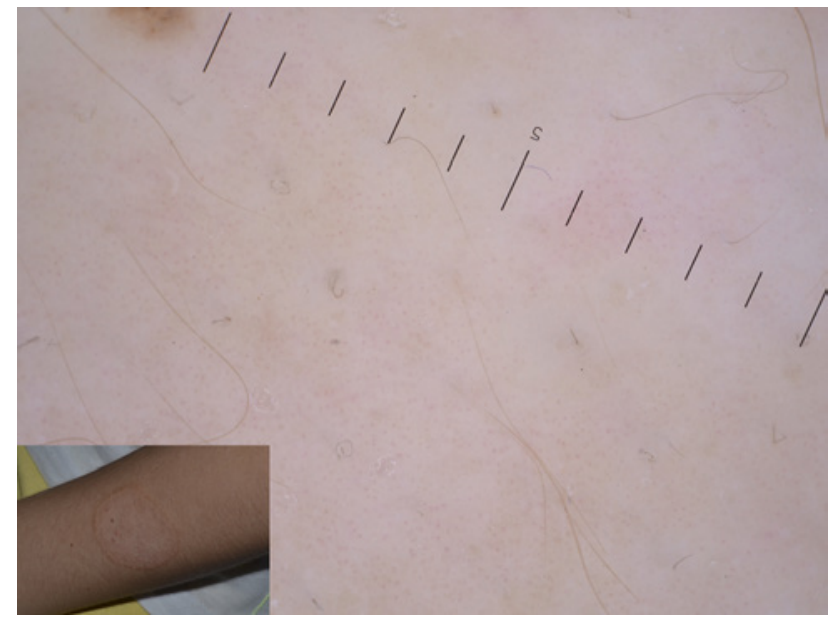

Figure 12. Newly described vellus hair involvement in tinea corporis, identified by black dystrophic hair.

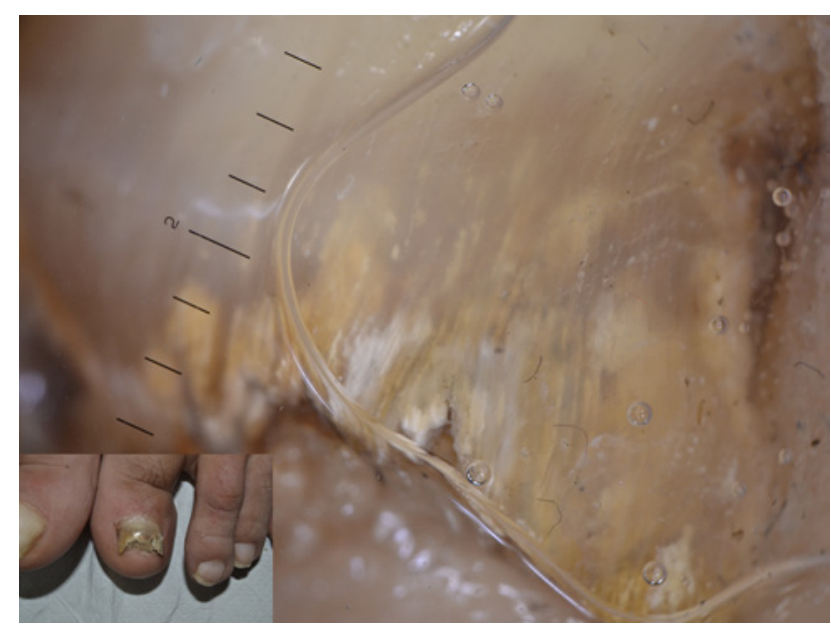

Figure 14. Onychomycosis showing fringed proximal onycholytic border associated with longitudinal striae.

indicated that Morse code-like hair could be secondary to ectothrix-type hair parasitization secondary to Microsporum infection, whereas black dots and dystrophic hair mostly associated to Trichophyton infection, even if these data should be confirmed by larger studies.

Tinea corporis. Numerous papers have been published about dermoscopic findings in tinea capitis, but only a limited amount of novel information is now available about dermoscopy of tinea corporis. In particular, the presence of black dots surrounded by a pale whitish halo could indicate the involvement of vellus hair (Figure 12) and the need for systemic antifungal treatment [14]. Similar findings have been recently reported in tinea incognito (Figure 13) and Majocchi granuloma in association with small pustules $[15,16]$.

Tinea manuum. Lately, dermoscopy of tinea manuum has been reported, showing predominant scaling associated with dotted vessels detectable in the furrows $[17,18]$.

Onychomycosis. Onychomycosis is listed in the group of dermatophytic infections, as dermatophytes are responsible

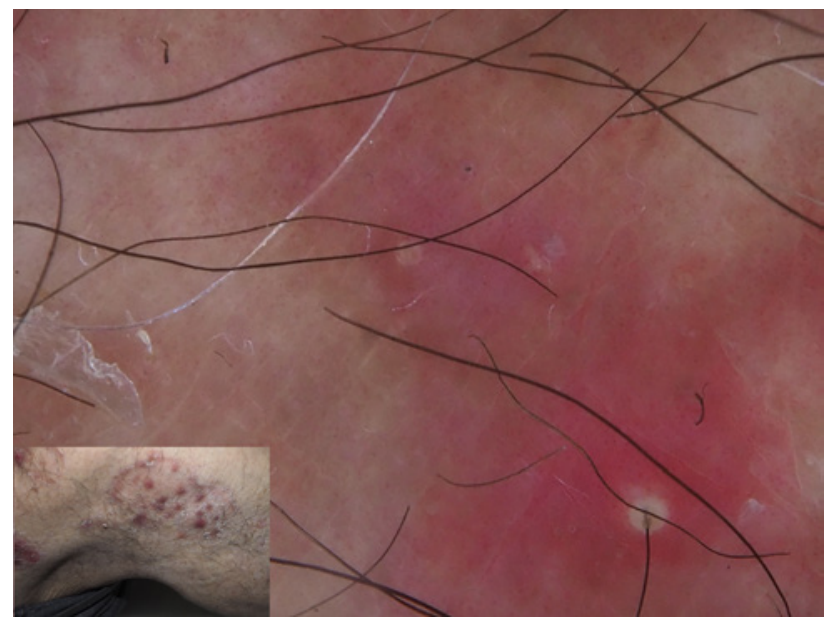

Figure 13. A challenging diagnosis of tinea incognito could be favored by dermoscopy showing vellus hair involvement and pustules.

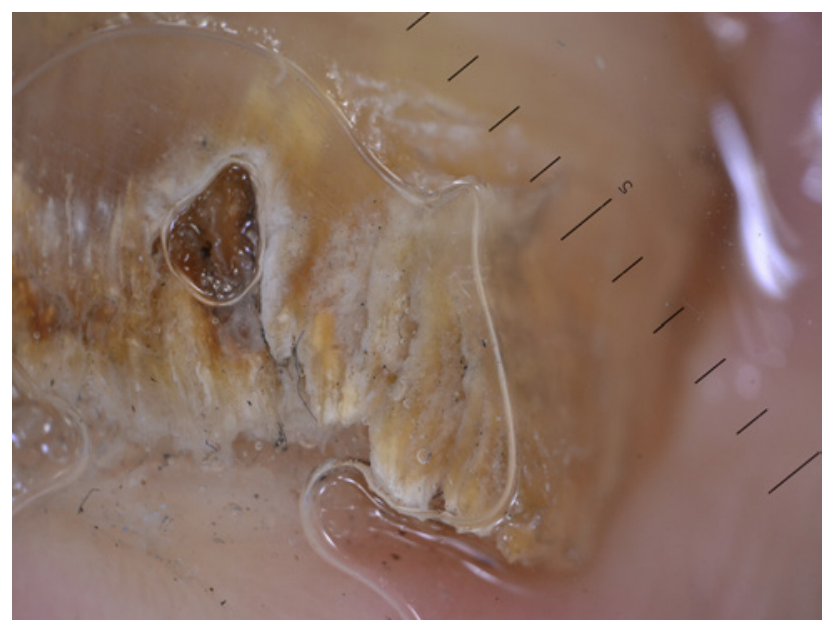

Figure 15. Ruin-like appearance of distal border of nail seen at dermoscopy.

for most fungal nail infections. In recent years several studies have shown the utility of onychoscopy in the diagnosis of onychomycosis. In a recent clinical overview in the Journal of the American Academy of Dermatology, onychoscopy was recognized as a supportive tool for the diagnosis of onychomycosis $[19,20]$ and its differential diagnosis [21]. The most common dermoscopic finding is the fringed proximal onycholytic border, associated with longitudinal striae with fading resembling "aurora borealis" (Figure 14), and ruinlike appearance of the subungual hyperkeratosis and debris (Figure 15). Recently, onychoscopy of fungal melanonychia has been described with different colors in nail discoloration including black, white, yellow, and orange, allowing a differential diagnosis with malignant melanonychia [20,22,23].

\section{Pediculosis}

Head lice. Pediculosis capitis (or head lice) is a worldwide diffuse infestation due to Pediculus humanus capitis that 


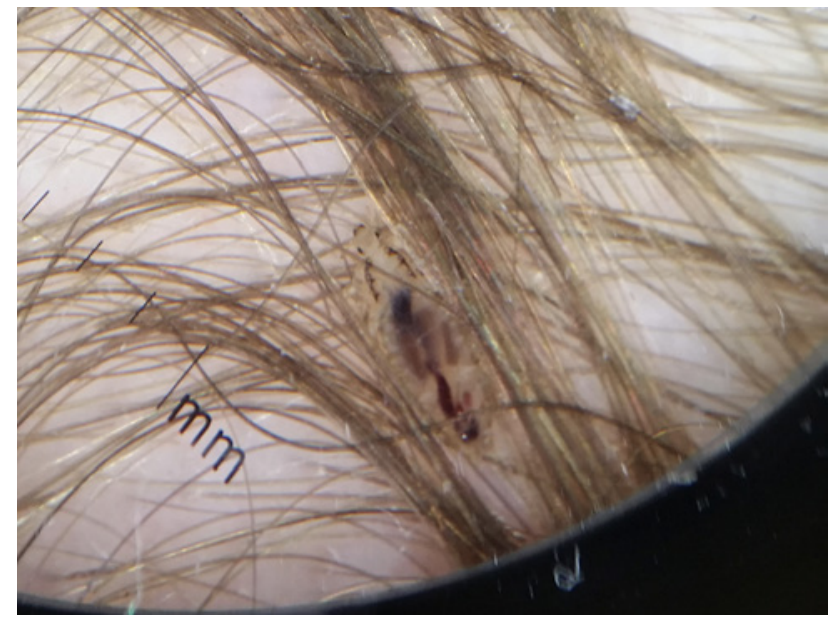

Figure 16. Rare picture of pediculus capitis seen at dermoscopy.

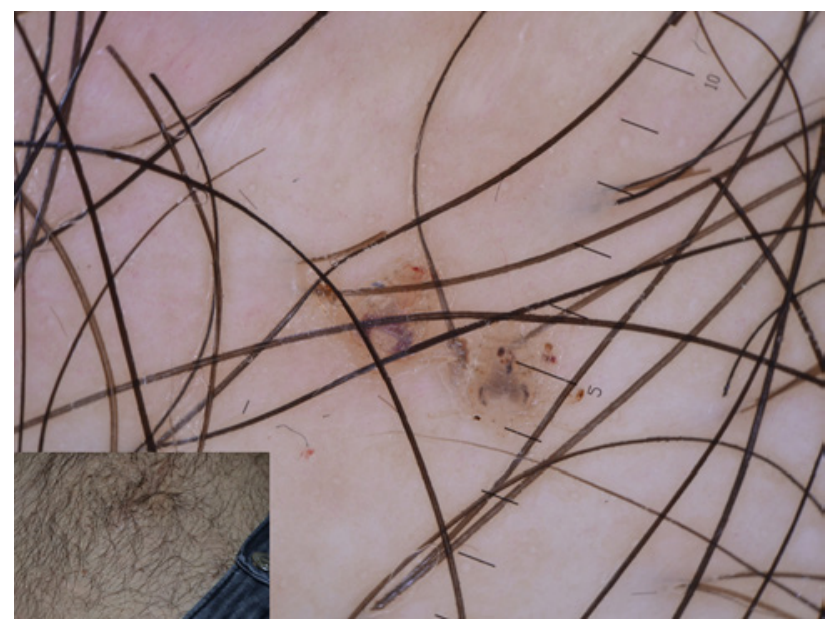

Figure 18. A couple of Pthirus found on the pubis of young man. Note the scorpion-like appearance of blood-filled intestine.

is usually quite easy to diagnose. Diagnostic delay may be provoked by low socioeconomic level and by the interval between the infestation and the appearance of the main symptom of pediculosis, namely the itch occurring a few weeks later. The diagnosis is immediate when the parasites are seen at the inspection of scalp hair, but it is not always so easy, especially in patients with scaling conditions of the scalp (psoriasis, seborrheic dermatitis) and when panic is diffuse among communities where pediculosis is spreading. The detection of lice (Figure 16) is difficult through the dermatoscope [7]. Conversely, nits are well recognizable through trichoscopic examination as ovoid structures anchored to the hair shaft, which appear brown when still vital and translucent with a sharp free end when empty (Figure 17). Through dermoscopy nits can be distinguished from pseudonits, such as hair casts appearing as cylindrical whitish structures surrounding the hair shaft and easy to remove [7].

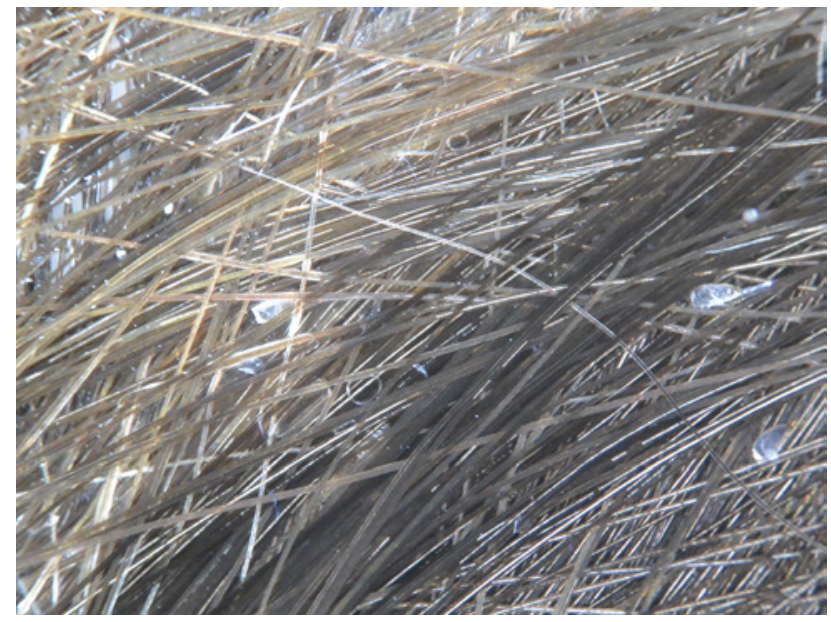

Figure 17. Nits adherent to hair shafts highly diagnostic in pediculosis capitis.

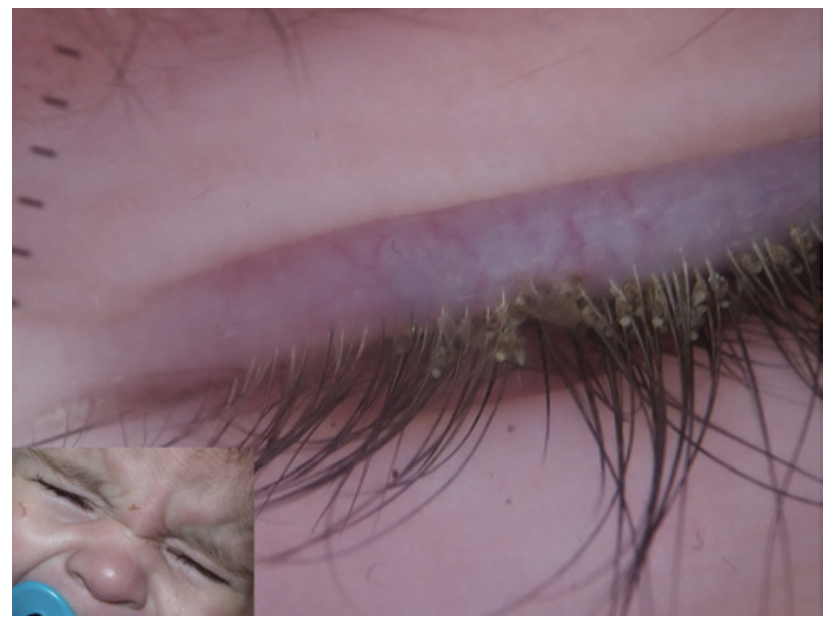

Figure 19. Nits and lice adherent to eyelashes in a child affected by pthiriasis palpebrarum.

Pthirus pubis. Unlike head lice, Pthirus pubis is predominantly a sexually transmitted disease among adults that usually appears with itch in the pubic and genital area. Dermoscopy confirms the clinical suspicion by direct detection of the Pthirus, whose body is more flattened and larger than pediculus capitis, adherent to pubic hairs and blood-feeding. The blood-filled intestine of Pthirus resembles the body of a scorpion (personal observation) (Figure 18). Nits can be detected in Pthirus pubis as well. Pthirus could potentially affect children as well, whose infection is transmitted by adults. Pediatric Pthirus usually occurs on the eyelashes, and less frequently eyebrows, and hair with dermoscopy playing a key role for the detection of the parasite (Figure 19), its prompt treatment and follow-up [7].

\section{What's New?}

No great news is available about dermoscopy of pediculosis, except a paper about the use of the dermatoscope for the diagnosis of pediculosis corporis [24]. 


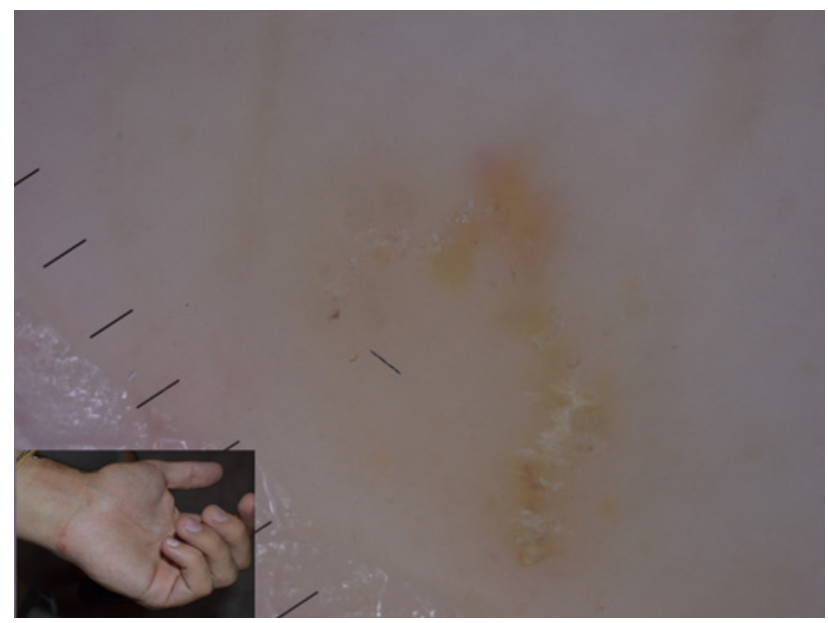

Figure 20. Delta-wing jet with contrail sign in scabies.

\section{Scabies}

Scabies is undoubtedly in general dermatology the skin disease whose diagnosis has gained most advantage by the use of the dermatoscope. Indeed, dermoscopy has revolutionized the approach to the diagnosis of scabies in the last decade. Scabies lacks clinical specific and diagnostic features and, traditionally, diagnosis is based on the severe itch and cutaneous lesions appearing in preferential body areas, such as wrists, finger web spaces, axillae, and genitals. The burrow produced by the female mite is highly diagnostic, but hard to detect by the naked eye. Before dermoscopy, diagnostic confirmation of scabies was given by the direct observation of mite, feces, and eggs after casual skin scraping, but the sensitivity of this test is low and its reliability is operator-sensitive. The so called delta-wing jet with contrail sign is probably the most notorious dermoscopic picture ever and represents the irregular burrow excavated by the mite, whose anterior part of the body is visible at dermoscopy as a small black arrowhead area at the end of the whitish wavy line [25] (Figure 20). Nowadays, this finding is considered pathognomonic for scabies, regardless of the patient's age, the location of the lesion, and type and duration of the infection.

\section{What's New?}

Recently, a novel dermoscopic sign was described in Norwegian scabies, namely the "noodle sign" [26] (Figure 21), ie, an accumulation of hundreds of burrows in the same dermoscopic field, given the patient's immunosuppression and the consequent disease severity. Another quite recent finding is related to neonatal scabies [27], whose dermoscopy has lately been described as similar to that found in adults but with a different, more precocious and non-itchy occurrence of cutaneous nodules in these very young patients (Figure 22).

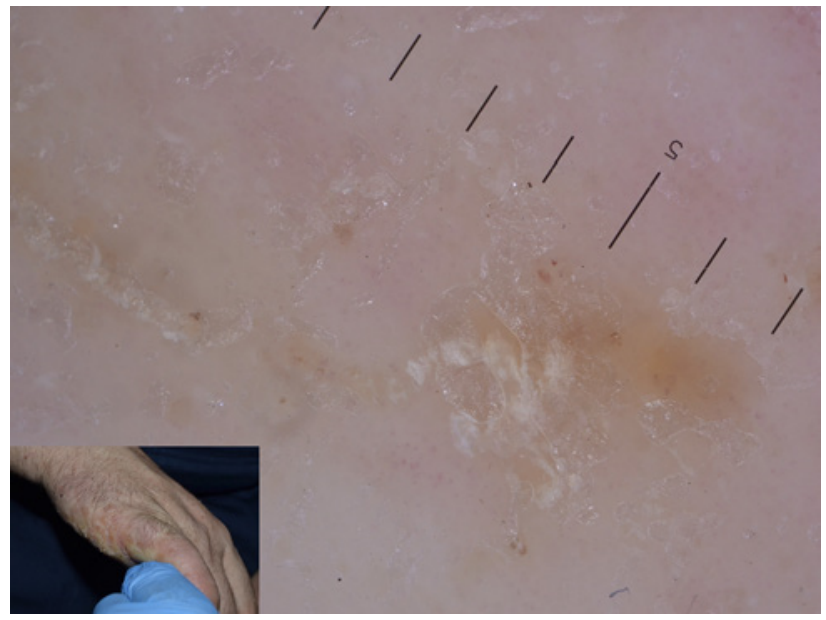

Figure 21. Grouped mite burrows configuring the "noodle sign" in crusted scabies.

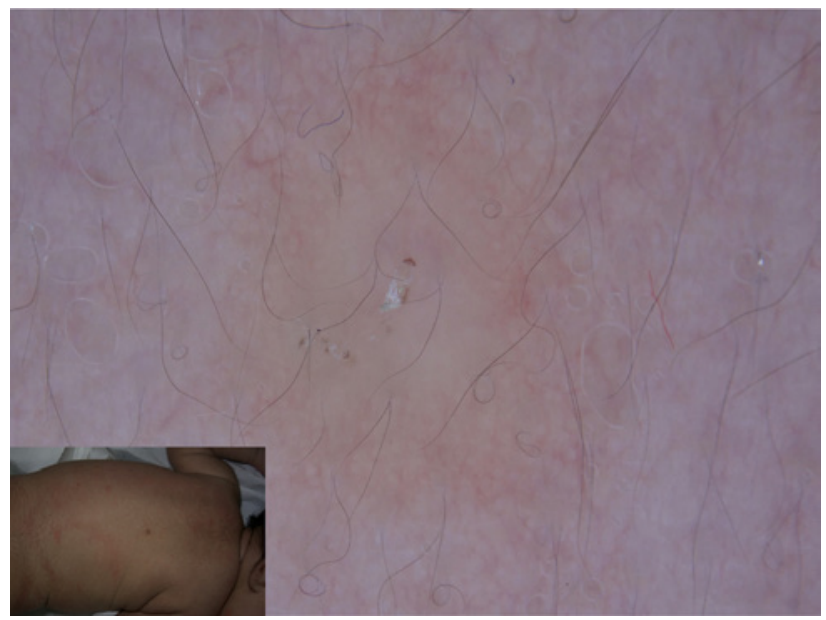

Figure 22. Nodular scabies of newborn detected at dermoscopy.

\section{Tinea Nigra}

Tinea nigra is a relatively uncommon dematiaceous fungal infection, usually caused by Phaeoannellomyces werneckii. Tinea nigra is diffuse in the tropical and subtropical areas of Central and South America, Africa, and Asia. It often occurs as occasional infection after traveling in these areas of the world. It usually affects young people and presents as an irregular acral pigmentation that may mimic a melanocytic lesion. Dermoscopy typically shows a weak pigmentation composed of thin bundles of spicules, arranged in parallel lines mainly in some peripheral areas (Figure 23) [28-31]. The pigmentation usually does not follow the dermatoglyphic furrow and ridges, although in some cases the parallel ridge pattern could be hard to distinguish from acral melanoma [28-31].

\section{Tungiasis}

Tungiasis is a parasitic infection due to Tunga penetrans, which is endemic in Africa, Central America, Asia, and Carib- 


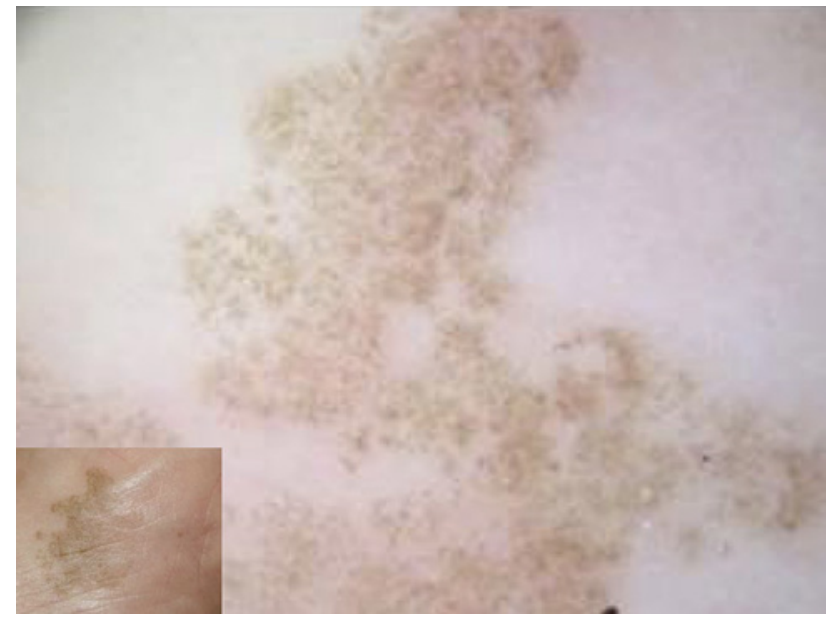

Figure 23. Typical findings of tinea nigra showing weak pigmentation composed of thin bundles of spicules, arranged in parallel lines mainly in some peripheral areas.

bean and is occasionally seen in Europe and North America in travelers. Barefoot walking on sand contaminated by pigs' and cows' feces favors contact with the impregnated parasite, which penetrates through the skin and feeds on the host's blood.

As a consequence, tungiasis clinically presents as a small whitish plantar hyperkeratosis with a central black area, often misdiagnosed as plantar wart. Dermoscopy plays an important role in differential diagnosis and typically shows a homogeneous white area centered by a black pore (Figure 24), which represents the pigmented chitin around the exoskeleton of Tunga [32]. Eggs enclosed in the jelly-bag can be detected as ovoid gray-blue structures in proximity to the central pore and disposed in a chain-like fashion. Expelled eggs can rarely be seen. Ex vivo dermoscopy may be useful for the confirmation of the diagnosis, allowing direct visualization of the parasite.

\section{Leishmaniasis}

Leishmaniasis is an infection provoked by the protozoa Leishmania whose reservoirs are dogs and rodents, that occasionally affects humans through the vectors sandflies. Leishmaniasis is diffuse worldwide, with different species predominating in each part of the world. Cutaneous leishmaniasis (CL) usually occurs as single or multiple nodules or plaque appearing in the area of protozoan inoculation. Lesions often present a serous crust covering an ulceration. Although clinical appearance could be enough to suspect CL, diagnosis could be challenging in most cases, above all in nonendemic areas $[33,34]$. Dermoscopy of CL was described for the first time in 2009. The most common finding was generalized erythema, followed by a very characteristic feature, namely "yellow tears" (Figure 25). The latter are yellowish white round-to-oval structures. Moreover,

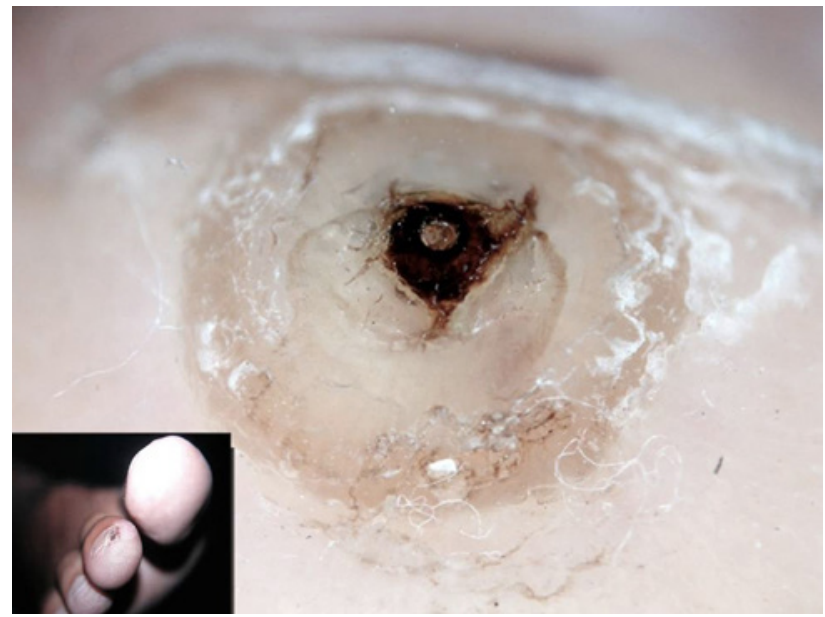

Figure 24. Dermoscopy of tungiasis showing a homogeneous white area centered by a black pore.

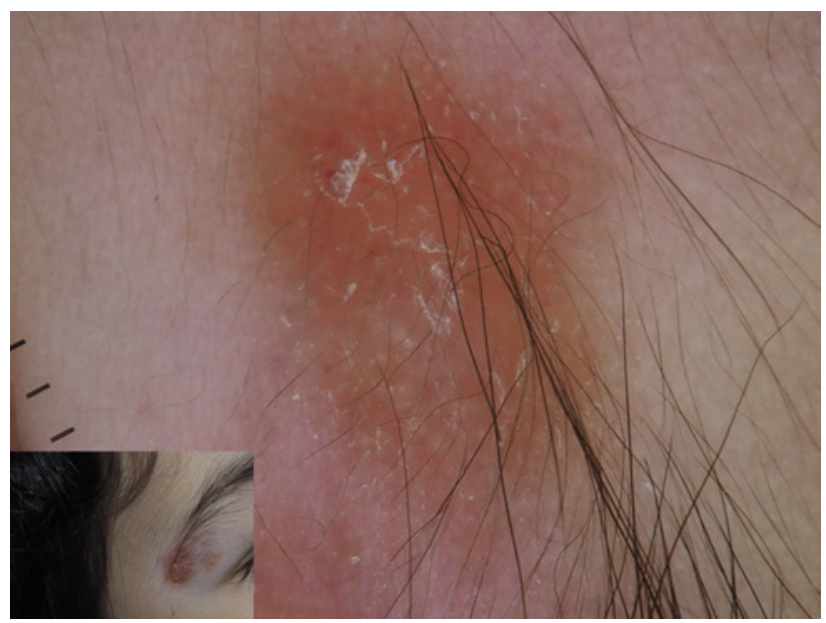

Figure 25. A child affected by cutaneous leishmaniasis showing at dermoscopy yellow tears on a reddish orange background.

hyperkeratosis, central erosion or ulceration, and "white starburst-like pattern" may be observed. Vascular structures are often detectable with variable morphology (dotted, linear, polymorphous, hairpin, mixed) [33]. A recent larger study published in Dermatology: Practical and Conceptual has confirmed these findings [34].

\section{Cutaneous Larva Migrans}

Cutaneous larva migrans is a tropical infection due to Ancylostoma, whose reservoir is dogs' and cats' intestine. The most common nematode provoking the so-called creeping eruption is the Ancylostoma braziliense, diffuse in North, Central, and South America and Caribbean. It usually presents as a quite typical serpiginous, linear, slightly elevated, itchy erythema occurring on the feet, web spaces, arms, or buttocks [35]. Dermoscopy shows multiple translucent yellow-brown structureless areas arranged in a segmental fashion (Figure 26), 


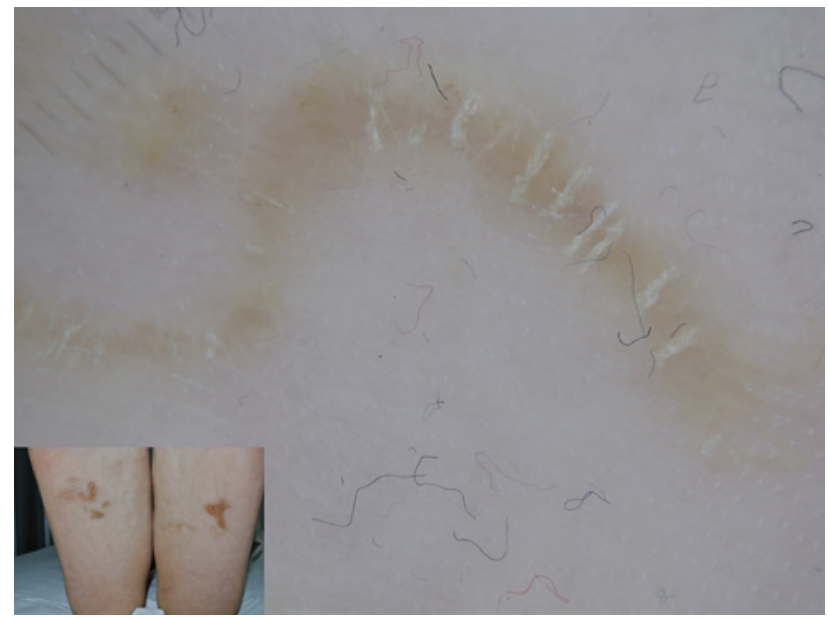

Figure 26. Segmented serpiginous appearance of larva migrans at dermoscopy.

which represent the body of the worm, with dotted vessels detectable where the burrow is empty [35].

\section{Other Diseases}

With the spread of dermoscopy in dermatology, numerous novel findings in different infectious diseases have been described.

\section{What's New?}

Pseudomonas onychopathy may be quickly detected through dermoscopy for the green nail discoloration provoked by the production of the pigment pyocyanin [36] (Figure 27). Trichomycosis axillaris has been found to show at dermoscopy yellowish hair casts around axillary hairs [37] (Figure 28). Differential diagnosis through dermoscopy of different types of folliculitis has been proposed [38].

\section{Conclusions and Future Perspectives}

One of the most fascinating aspects of dermoscopy is that it looks like a never-ending science, with news published frequently. Diagnostic approach to infectious diseases is different nowadays also thanks to the dermatoscope, which has progressively increased diagnostic confidence with rarer diseases, such as leishmaniasis, tungiasis, and larva migrans. It is important to state that dermoscopy is not the unique diagnostic tool for most infectious diseases of the skin and should be considered supportive and not a substitute for the other well-known diagnostic techniques, such as potassium hydroxide examination and histology. The low cost of the handheld instrument and the spread of the technique among dermatologists all over the world will probably provide more details about less common tropical infectious diseases whose diagnosis is still challenging for most dermatologists.

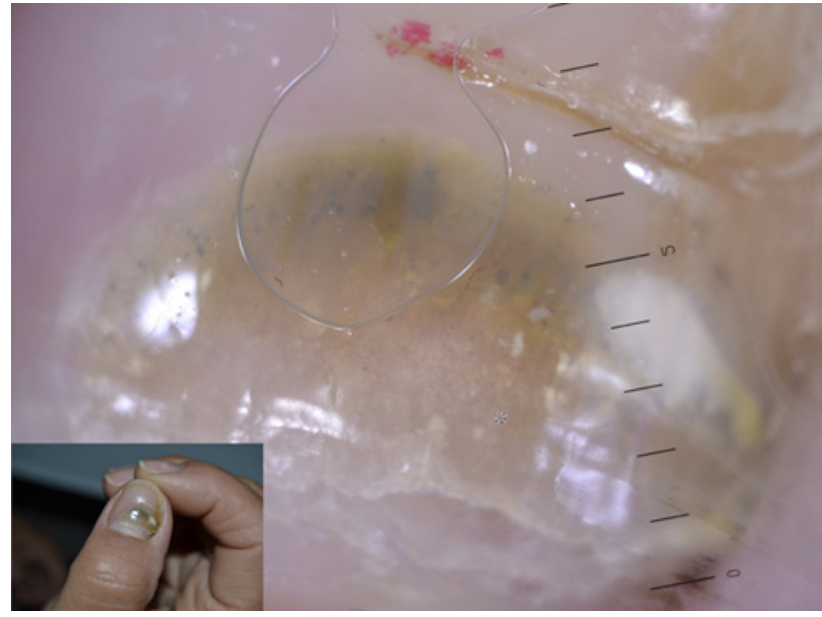

Figure 27. Yellow-to-green discoloration of the nail at dermoscopic examination of nail plate.

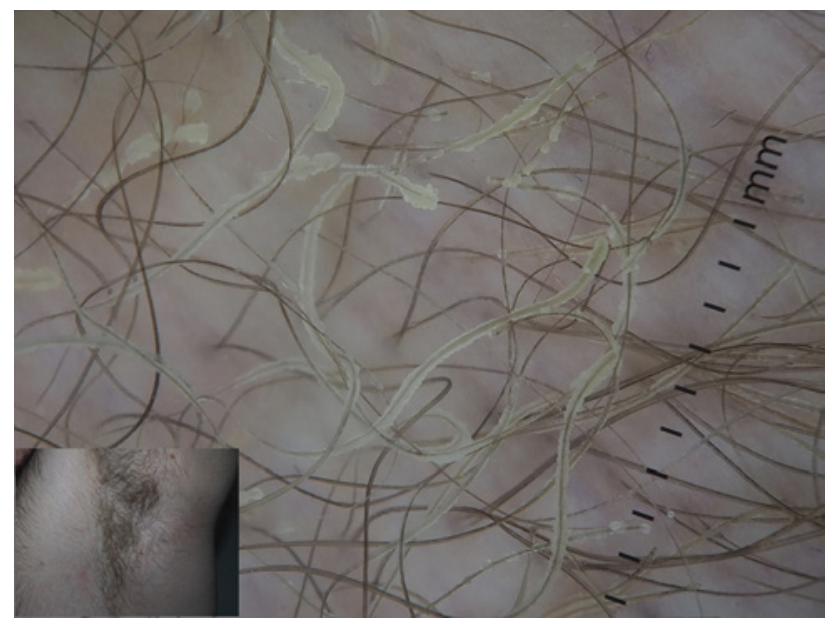

Figure 28. Dermoscopic appearance of trichomycosis axillaris showing yellowish hair casts around axillary hairs.

\section{References}

1. Russo T, Piccolo V, Lallas A, Argenziano G. Recent advances in dermoscopy. F1000Res. 2016 Feb 17;5. pii: F1000 Faculty Rev184. doi:10.12688/f1000research.7597.1.

2. Zalaudek I, Lallas A, Moscarella E, Longo C, Soyer HP, Argenziano G. The dermatologist's stethoscope-traditional and new applications of dermoscopy. Dermatol Pract Concept. 2013;3(2):67-71.

3. Argenziano G, Fabbrocini G, Delfino M. Epiluminescence microscopy: a new approach to in vivo detection of Sarcoptes scabiei. Arch Dermatol. 1997;133(6):751-753.

4. Errichetti E, Zalaudek I, Kittler H, et al. Standardization of dermoscopic terminology and basic dermoscopic parameters to evaluate in general dermatology (non-neoplastic dermatoses): an expert consensus on behalf of the International Dermoscopy Society. Br J Dermatol. 2019 May 11. doi: 10.1111/bjd.18125. Epub ahead of print.

5. Kelly SC, Purcell SM. Prevention of nosocomial infection during dermoscopy? Dermatol Surg. 2006;32(4):552-555.

6. Penso-Assathiany D, Gheit T, Prétet JL, et al. Presence and persistence of human papillomavirus types 1, 2, 3, 4, 27, and 57 on 
dermoscope before and after examination of plantar warts and after cleaning. J Am Acad Dermatol. 2013;68(1):185-186.

7. Tschandl P, Argenziano G, Bakos R, et al. Dermoscopy and entomology (entomodermoscopy). J Dtsch Dermatol Ges. 2009;7(7):589-596.

8. Zhang Y, Jiang S, Lin H, Guo X, Zou X. Application of dermoscopy image analysis technique in diagnosing urethral condylomata acuminata. An Bras Dermatol. 2018;93(1):67-71.

9. Ianhez M, Cestari Sda C, Enokihara MY, Seize MB. Dermoscopic patterns of molluscum contagiosum: a study of 211 lesions confirmed by histopathology. An Bras Dermatol. 2011;86(1):74-79.

10. Ku SH, Cho EB, Park EJ, Kim KH, Kim KJ. Dermoscopic features of molluscum contagiosum based on white structures and their correlation with histopathological findings. Clin Exp Dermatol. 2015;40(2):208-210.

11. Slowinska M, Rudnicka L, Schwartz RA, et al. Comma hairs: a dermatoscopic marker for tinea capitis: a rapid diagnostic method. J Am Acad Dermatol. 2008;59(5 Suppl):S77-S79.

12. Lacarrubba F, Verzì AE, Micali G. Newly described features resulting from high-magnification dermoscopy of tinea capitis. JAMA Dermatol. 2015;151(3):308-310.

13. Wang HH, Lin YT. Bar code-like hair: dermoscopic marker of tinea capitis and tinea of the eyebrow. J Am Acad Dermatol. 2015;72(1 Suppl):S41-S42.

14. Knöpfel N, del Pozo LJ, Escudero Mdel M, Martín-Santiago A. Dermoscopic visualization of vellus hair involvement in tinea corporis: a criterion for systemic antifungal therapy? Pediatr Dermatol. 2015;32(5):e226-e227.

15. Piccolo V, Corneli P, Russo T, Zalaudek I, Alfano R, Argenziano G. Dermoscopy as a useful tool in diagnosis of tinea incognito. Int J Dermatol. 2019;58(2):e32-e34.

16. Piccolo V, Di Brizzi EV, Russo T, et al. Majocchi's granuloma on the face: dermoscopy and reflectance confocal microscopy. Int $J$ Dermatol. 2019;58(9):e180-e182.

17. Errichetti E, Stinco G. Dermoscopy in tinea manuum. An Bras Dermatol. 2018;93(3):447-448.

18. Jakhar D, Kaur I, Sonthalia S. Dermoscopy of tinea manuum. Indian Dermatol Online J. 2019;10(2):210-211.

19. Piraccini BM, Balestri R, Starace M, Rech G. Nail digital dermoscopy (onychoscopy) in the diagnosis of onychomycosis. J Eur Acad Dermatol Venereol. 2013;27(4):509-513.

20. Lipner SR, Scher RK. Onychomycosis: clinical overview and diagnosis. J Am Acad Dermatol. 2019;80(4):835-851.

21. Piccolo V, Argenziano G, Alessandrini AM, Russo T, Starace M, Piraccini BM. Dermoscopy of subungual exostosis: a retrospective study of 10 patients. Dermatology. 2017;233(1):80-85.

22. Russo T, Piccolo V, Lallas A, et al. Dermoscopy of malignant skin tumours: what's new? Dermatology. 2017;233(1):64-73.
23. Russo T, Piccolo V, Panarese I, Alfano R, Argenziano G. A challenging toenail melanonychia. J Dtsch Dermatol Ges. 2019;17(1):85-86.

24. Martins LG, Bernardes Filho F, Quaresma MV, Bellott TR, Botelho LN, Prata AC. Dermoscopy applied to pediculosis corporis diagnosis. An Bras Dermatol. 2014;89(3):513-514.

25. Argenziano G, Fabbrocini G, Delfino M. Epiluminescence microscopy: a new approach to in vivo detection of Sarcoptes scabiei. Arch Dermatol. 1997;133(6):751-753.

26. Chavez-Alvarez S, Villarreal-Martinez A, Argenziano G, Ancer-Arellano J, Ocampo-Candiani J. Noodle pattern: a new dermoscopic pattern for crusted scabies (Norwegian scabies). J Eur Acad Dermatol Venereol. 2018;32(2):e46-e47.

27. Neri I, Chessa MA, Virdi A, Patrizi A. Nodular scabies in infants: dermoscopic examination may avoid a diagnostic pitfall. J Eur Acad Dermatol Venereol. 2017;31(12):e530-e531.

28. Smith SB, Beals SL, Elston DM, Meffert JJ. Dermoscopy in the diagnosis of tinea nigra plantaris. Cutis. 2001;68(6):377-380.

29. Piliouras P, Allison S, Rosendahl C, Buettner PG, Weedon D. Dermoscopy improves diagnosis of tinea nigra: a study of 50 cases. Australas J Dermatol. 2011;52(3):191-194.

30. Noguchi H, Hiruma M, Inoue Y, Miyata K, Tanaka M, Ihn H. Tinea nigra showing a parallel ridge pattern on dermoscopy. $J$ Dermatol. 2015;42(5):518-520.

31. Nazzaro G, Ponziani A, Cavicchini S. Tinea nigra: a diagnostic pitfall. J Am Acad Dermatol. 2016;75(6):e219-e220.

32. Bauer J, Forschner A, Garbe C, Röcken M. Dermoscopy of tungiasis. Arch Dermatol. 2004;140(6):761-763.

33. Llambrich A, Zaballos P, Terrasa F, Torne I, Puig S, Malvehy J. Dermoscopy of cutaneous leishmaniasis. Br J Dermatol. 2009;160(4):756-761.

34. Serarslan G, Ekiz Ö, Özer C, Sarıkaya G. Dermoscopy in the diagnosis of cutaneous leishmaniasis. Dermatol Pract Concept. 2019;9(2):111-118.

35. Aljasser MI, Lui H, Zeng H, Zhou Y. Dermoscopy and near-infrared fluorescence imaging of cutaneous larva migrans. Photodermatol Photoimmunol Photomed. 2013;29(6):337-338.

36. Romaszkiewicz A, Sławińska M, Sobjanek M, Nowicki RJ. Nail dermoscopy (onychoscopy) is useful in diagnosis and treatment follow-up of the nail mixed infection caused by Pseudomonas aeruginosa and Candida albicans. Postepy Dermatol Alergol. 2018;35(3):327-329.

37. Rojas Mora E, Freites Martínez A, Hernández-Núñez A, Borbujo Martínez J. Trichomycosis axillaris: clinical, Wood lamp, and dermoscopic diagnostic images. Actas Dermosifiliogr. 2017;108(3):264-266.

38. Durdu M, Errichetti E, Eskiocak AH, Ilkit M. High accuracy of recognition of common forms of folliculitis by dermoscopy: an observational study. J Am Acad Dermatol. 2019;81(2):463-471. 